\title{
CONSTRUÇÃO DE PLATAFORMAS E LANÇAMENTOS DE FOGUETES PARA O DESENVOLVIMENTO DE HABILIDADES DA ÁREA DE CIÊNCIAS DA NATUREZA, MATEMÁTICA E SUAS TECNOLOGIAS
}

\author{
Bruno Alves dos Santos ${ }^{1}$ \\ Renata Maciel de Faria ${ }^{2}$ \\ Bianca Sena Marques ${ }^{3}$ \\ Marcos Vinicios Siqueira da Silva ${ }^{4}$ \\ Samuel Negreiros Ferreira ${ }^{5}$ \\ Celso Lucas de Lima Santos ${ }^{6}$ \\ Matheus de Souza Lapa ${ }^{7}$ \\ Helder Faria ${ }^{8}$ \\ Valquiria Tereza Valério Martins ${ }^{9}$
}

Resumo: O projeto iniciado em 2014 teve continuidade pelos alunos da escola E.E.E.I Professor Nelson do Nascimento Monteiro e apresenta as atividades práticas desenvolvidas na Mostra Brasileira de Foguetes (MOBFOG) em 2014, 2015 e 2016, bem como na Jornada de Foguetes em 2014 e 2015. Durante as aulas semanais da Disciplina Eletiva "Caminhos da Ciência" foram produzidos acervos de fotos e vídeos, relatório técnico explicando a construção dos foguetes, dos testes para o propelente e a introdução de cada parte do propelente dentro do foguete, e, realizadas novas pesquisas para entender sobre a aerodinâmica dos foguetes com o objetivo de inovar tanto na construção de novos foguetes como na nova plataforma híbrida de lançamentos agora partindo da teoria para a prática.

Palavras-chave: MOBFOG; Foguetes; Equipe; Construção; Plataforma.

\footnotetext{
1 Ensino Médio/EEEI Prof. Nelson do Nascimento Monteiro, Brasil. E-mail: brunosantosbr1117@gmail.com.

2 Ensino Médio/EEEI Prof. Nelson do Nascimento Monteiro, Brasil. E-mail: magumf@gmail.com.

${ }^{3}$ Ensino Médio/EEEI Prof. Nelson do Nascimento Monteiro, Brasil. E-mail: Ivtv@ig.com.br.

${ }^{4}$ Ensino Médio/EEEI Prof. Nelson do Nascimento Monteiro, Brasil. E-mail: marcosbigmax@gmail.com.

5 Ensino Médio/EEEI Prof. Nelson do Nascimento Monteiro, Brasil. E-mail: samuel.negreiros@hotmail.com.

${ }^{6}$ Ensino Médio/EEEI Prof. Nelson do Nascimento Monteiro, Brasil. E-mail: celso.lima0909@gmail.com.

7 Ensino Médio/EEEl Prof. Nelson do Nascimento Monteiro, Brasil. E-mail: teteulapa@gmail.com.

8 Ensino Médio/EEEI Prof. Nelson do Nascimento Monteiro, Brasil. E-mail: profheder@ig.com.br.

${ }^{9}$ Ensino Médio/EEEI Prof. Nelson do Nascimento Monteiro, Brasil. E-mail: valquiriatvm@gmail.com.
} 